Check for updates

The BMJ

Cite this as: BMJ 2020;370:m3224 http://dx.doi.org/10.1136/bmj.m3224 Published: 14 August 2020

\section{Covid-19: Nearly $6 \%$ of people in England were infected by end of June, study suggests}

Gareth lacobucci

Some 3.4 million people in England-just under 6\% of the population-are likely to have been infected with covid-19 by the end of June, a large antibody surveillance study has found.

Minority ethnic groups, people working in care homes and healthcare, and people living in larger households were more likely to have contracted the virus, showed preliminary findings from the Real-time Assessment of Community Transmission-2 (REACT2) trial.

Speaking at a Science Media Centre briefing to discuss the study, Helen Ward, the lead study author and professor of public health at Imperial College London, said, "The epidemic is widespread, but its impact has been socially very unequal. We really need to think about how to provide greater protection for those at highest risk."

The study, which has not yet been peer reviewed, is the second part of the government commissioned REACT trial and was carried out by Imperial College in partnership with the polling company Ipsos MORI. It gathered 5544 results from 109076 volunteers in England who tested themselves at home for SARS-CoV-2 antibodies with finger prick tests from 20 June to 13 July 2020, uploading results through an online survey.

\section{Antibodies and ethnicity}

The findings, available in a preprint report submitted to medRxiv, ${ }^{1}$ show that the prevalence of antibodies was $6 \%$ (95\% confidence interval $5.8 \%$ to $6.1 \%$ ). The authors estimated that 3.36 million (3.21 million to 3.51 million) people had been infected with SARS-CoV-2 in England by the end of June 2020, with an overall infection fatality rate of $0.9 \%$ (0.86\% to $0.94 \%)$.

This estimate is substantially higher than the recorded numbers of 315000 cases in the UK and 267000 in England.

People of black (including black Caribbean, black African, and black British) ethnicity (17.3\% (15.8 to 19.1)) and Asian (mainly south Asian) ethnicity (11.9\% (11.0 to 12.8)) were two to three times more likely to have antibodies than people of white ethnicity ( $5 \%$ ( 4.8 to 5.2$)$ ).

This gap was reduced after the researchers considered factors such as age and employment, but rates were still higher overall in ethnic minority respondents. The researchers suggested that other factors not explored in the study, such as transport use and behaviour, could therefore be linked to the higher likelihood of infection.

Graham Cooke, NIHR research professor of infectious diseases and research lead at Imperial, said, "We know clearly there are differences in mortality between ethnic groups, with higher mortality in black and ethnic populations. The data here is probably now the most robust we've got to say that this is likely a consequence of the differences in infection acquisition."

\section{Employment and households}

Frontline workers in care homes (16.5\% (13.7\% to 19.8\%)) and healthcare workers with patient contact (11.7\% $(10.5 \%$ to $13.1 \%)$ ) had higher infection rates than people in other forms of employment (5.3\% (5.0\% to 5.6\%)).

A much higher prevalence was found in people from the most deprived areas $(7.3 \%(6.8 \%$ to $7.7 \%))$ than in those from the least deprived ( $5 \%(4.6 \%$ to $5.4 \%)$ ). And people living in households of more than seven people $(13 \%(11.0 \%$ to $15.3 \%)$ ) were more than twice as likely to have been infected than those living alone $(4.7 \%(4.3 \%$ to $5.1 \%))$ or with one other person $(5 \%(4.7 \%$ to $5.3 \%))$.

Regionally, the highest prevalence was in London (13\% (12.3\% to 13.6\%)) and the lowest in the south west $(2.8(2.4 \%$ to $3.3 \%))$. In terms of age, young people aged 18 to 24 had the highest rates $(8 \%)$, and older adults aged 65 to 74 had the lowest $(3 \%)$.

Antibodies were found in $96 \%$ of people who had a previous infection confirmed by a swab test. The results were adjusted to account for the performance of the device and sample distribution.

Ward, the lead author, said the results suggested that the methods used in the study were "a sustainable model for ongoing surveillance."

\footnotetext{
Ward H, Atchison C, Whitaker M, et al. Antibody prevalence for SARS-CoV-2 following the peak of the pandemic in England: REACT2 study in 100000 adults. Aug 2020. https://www.imperial.ac.uk/media/imperial-college/institute-of-global-health-innovation/Ward-et-al-120820.pdf.
} 
This article is made freely available for use in accordance with BMJ's website terms and conditions for the duration of the covid-19 pandemic or until otherwise determined by BMJ. You may use, download and print the article for any lawful, non-commercial purpose (including text and data mining) provided that all copyright notices and trade marks are retained. 